\title{
Publisher Correction to: Algebraic structures and position-dependent mass Schrödinger equation from group entropy theory
}

\author{
Ignacio S. Gomez ${ }^{1}(\mathbb{0})$ Ernesto P. Borges ${ }^{1}$ (1)
}

Published online: 17 May 2021

( ) The Author(s), under exclusive licence to Springer Nature B.V. 2021

\section{Correction to: Letters in Mathematical Physics (2021) 111:43 https://doi.org/10.1007/s11005-021-01387-0}

The article was originally published without the authors' corrections; it has now been replaced by the corrected version.

The original article has been corrected.

Publisher's Note Springer Nature remains neutral with regard to jurisdictional claims in published maps and institutional affiliations.

The original article can be found online at https://doi.org/10.1007/s11005-021-01387-0.

Ignacio S. Gomez

ignacio.sebastian@ufba.br

Ernesto P. Borges

ernesto@ufba.br

1 Instituto de Física, Universidade Federal da Bahia, Rua Barao de Jeremoabo, Salvador,

Bahia 40170-115, Brazil 